\title{
Informed Consent in the Nuclear Medicine Setting*
}

\author{
M. Sara Rosenthal \\ Program for Bioethics, Department of Internal Medicine, University of Kentucky, Lexington, Kentucky
}

\begin{abstract}
In the nuclear medicine setting, the task of obtaining informed consent for procedures that require it is frequently left to the nuclear medicine technologist. Unfortunately, a patient's signature on a consent form does not mean the patient has given informed consent, or what legal scholars call valid consent. On completion of this scholarly bioethics article, the reader will understand the troubled history that led to informed consent as social and regulatory policy. Additionally, the reader will discover the meaning of "informed consent," which includes 3 critical components: disclosure, decision-making capacity, and voluntariness. Finally, this article will discuss which nuclear medicine procedures require informed consent, how to assess whether patients have given informed consent, what to do when the patient refuses a procedure, and what to do when informed consent is unachievable.
\end{abstract}

Key Words: informed consent; ethics; nuclear medicine procedures; research ethics

J Nucl Med Technol 2011; 39:1-4

DOI: 10.2967/jnmt.110.083931

\section{$\mathbf{I}_{\mathrm{n}}$} $n$ the nuclear medicine setting, there is a false assumption that the supervising physician, the health care provider ethically obligated to obtain informed consent, has actually done so. Unfortunately, a patient's signature on a consent form does not mean the patient has given what the courts have established as valid consent, or what bioethicists call informed consent (1). Studies have demonstrated that the average patient does not understand the average radiology consent form (2). The attending physician ordering nuclear medicine procedures may not adequately explain the nature of the nuclear medicine tests or therapies ordered. Patients typically present to the nuclear medicine department without full knowledge of the nuclear medicine procedures. Because informed consent is not required for all nuclear medicine procedures (including most diagnostic procedures),

\footnotetext{
Received Oct. 6, 2010; revision accepted Dec. 28, 2010.

For correspondence or reprints contact: M. Sara Rosenthal, University of Kentucky College of Medicine, K522-740 S. Limestone St., Lexington, KY 40536.

E-mail: msrose2@email.uky.edu

*NOTE: FOR CE CREDIT, YOU CAN ACCESS THIS ACTIVITY THROUGH THE SNM WEB SITE (http://www.snm.org/ce_online) THROUGH MARCH 2013.

COPYRIGHT (c) 2011 by the Society of Nuclear Medicine, Inc.
}

patients may be submitting to low-risk procedures without giving consent-an ethically problematic situation. Procedures that do require informed consent comprise all therapeutic procedures (e.g., radioactive iodine therapy), cardiac procedures involving exercise or pharmacologic stress tests, procedures involving lumbar puncture, cerebral and LeVeen shunt studies, and all CT scans done with a contrast agent. The realities and complexities of patient care, as well as reduced hours for residents in academic medical centers (3), create numerous administrative and institutional barriers to obtaining informed consent for nuclear medicine procedures. Ultimately, the health care provider who must obtain the signature of the nuclear medicine patient on the consent form is the individual with the ethical obligation to ensure the patient has undergone an informed consent process. A procedure may have to be delayed until the appropriate health care provider can be located to obtain informed consent.

\section{BACKGROUND}

The doctrine of informed consent supports the ethical principle of autonomy, which obligates the physician to respect patients' rights to self-determination, guided by their stated wishes, preferences, and values. Informed consent became established as a legal requirement in U.S. health law in 3 landmark 1972 cases: Canterbury v. Spence (4), Cobbs v. Grant (5), and Wilkinson v. Vesey (6). All 3 cases involved patients who were not sufficiently informed about the risks of procedures; Wilkinson $v$. Vesey involved deep radiation therapy resulting in severe complications. In Canterbury v. Spence the court stated: "The patient's right of self-decision can be effectively exercised only if the patient possesses enough information to enable an intelligent choice. The patient should make his own determination on treatment. Informed consent is a basic social policy..." (4). This case established that "physician[s] should convey the risks of an operation when a reasonable person would be likely to attach significance to the risk in deciding whether or not to forgo the proposed therapy." In Cobbs v. Grant, the court stated: "To enable the patient to chart his course knowledgeably, reasonable familiarity with the therapeutic alternatives and their hazards becomes essential.... Therefore, we hold, as an integral part of the physician's overall obligation to the patient there is a duty of reasonable disclosure of the available choices with respect to proposed 
therapy and of the dangers inherently and potentially involved in each." (5). In Wilkinson v. Vesey, the court stated: "a physician is bound to disclose all the known material risks peculiar to the proposed procedure." (6). The definition of "material risk" in this case would mean a riskhowever unlikely - that has significant consequences for the patient or could threaten the patient's life.

The establishment of informed consent as an ethical requirement grew out of egregious medical abuses of human subjects and patients who were exploited in medical research. The 1947 Nuremberg Code, drafted in response to Nazi medical research atrocities, states: "The voluntary consent of the human subject is absolutely essential." (7). However, the Nuremberg Code was largely ignored by U.S. medical researchers (8), and medical abuses in the United States at that time included the infamous Tuskegee Syphilis Study (1932-1972), which involved 400 African American males who were studied but not treated for syphilis and who did not give informed consent. In 1995, it was discovered that during the Cold War, over 400 radiation experiments funded by the U.S. government were performed on human subjects without their consent (9), most in direct violation of the Nuremberg Code $(7,8)$.

Most recently, a medical historian, Susan M. Reverby, uncovered another egregious research experiment (1946-1948) funded by the U.S. government, which involved infecting Guatemalan subjects with syphilis without their consent, in order to perfect penicillin dosages for treating syphilis (10).

\section{THE ROAD TO U.S. MEDICAL ETHICS GUIDELINES}

The incident that led to the establishment of medical ethics guidelines was the publication in 1966 of a paper by a Harvard anesthesiologist, Henry Beecher (11), which exposed numerous unethical U.S. medical experiments that were going on at that time, including the Willowbrook experiment (1963-1966), in which mentally challenged patients were infected with hepatitis, and experiments at the Brooklyn Jewish Chronic Disease Hospital (1963), where elderly patients were injected with live cancer cells. Beecher's paper led to the development of research ethics guidelines culminating in the Belmont Report (12) and the establishment of core ethical principles to guide clinical research and patient care. These guidelines also took into consideration behavioral experiments that involved deception after psychologic harms resulted from the participation of human subjects in research led by Stanley Milgram (13) and Phillip Zimbardo (14).

As the blurring of medical research and medical treatment continued, the doctrine of informed consent became an important process for quality patient care.

\section{COMPONENTS OF INFORMED CONSENT}

The criteria for informed consent are not met by simply obtaining a signature on a form; they involve full disclosure about risks and benefits of procedures, and all appropriate treatment options (15-17). The criteria additionally involve assessing decision-making capacity (18) while ensuring that decisions are voluntarily made, free of coercive influences (19).

\section{What Is Disclosure?}

For disclosure to take place, "a description of the treatment; its expected effects (e.g., duration of hospital stay, expected time to recovery, restrictions on daily activities); information about relevant alternative options and their expected benefits and relevant risks; and an explanation of the consequences of declining or delaying treatment must be provided." (16). In the nuclear medicine setting, disclosure includes preprocedural preparation instructions and postprocedural care. A patient should also be given an opportunity to ask questions, and the patient's health care providers should be available to answer them (16).

\section{Decision-Making Capacity}

Appropriate decision-making capacity is essential for genuine informed consent. Decision-making capacity means that the patient demonstrates "understanding and appreciation" of the circumstances, as well as evidence of rationality in arriving at a decision $(17,18,20)$.

Assessing decision-making capacity is a crucial step in properly obtaining consent from a patient because capacity assessments protect patients from making decisions that could lead to harmful or catastrophic outcomes. Patients with impaired capacity may require a surrogate decision maker in critical care contexts, but in elective procedure contexts, delaying procedures or denying procedures for certain patients may be ethically justified. Decision-making capacity operates on a sliding scale that permits lesser standards of capacity for less consequential medical decisions (such as getting a flu shot) and requires higher standards of capacity for decisions of greater consequence (such as consenting to high-dose radioactive iodine therapy). The more serious the expected harm to the patient from acting on a choice, the higher should be the standard of decision-making capacity (21). However, no single standard for capacity is adequate for all decisions. The standard of capacity that is necessary depends on the risk involved and varies from low to high - the reason why a range of ancillary procedures in hospitals (such as phlebotomy), and several diagnostic procedures in nuclear medicine, do not require informed consent.

When patients do not understand the information relevant to a decision, or do not appreciate the reasonably foreseeable consequences of a decision or lack of decision, or are not able to decide about a procedure because not enough information has been disclosed, they are considered to lack genuine capacity to consent. Barriers to capacity can include pain medications, extreme anxiety or depression, and pain or discomfort.

When patients ask questions or make statements that signify they do not have a clear understanding of the procedure or appear to have underlying mental health pro- 
blems, the need to assess decision-making capacity or to revisit informed consent is signaled, because there may be a deficit in understanding and a lack of appreciation of risks and benefits.

If there is a question about capacity, the supervising or treating physician must be notified. It is this physician who must verify the presence of appropriate decision-making capacity, and it is this physician who must consult with mental health practitioners to rule out mental health problems. Clinical ethicists may also assist in determining whether deficits in information are barriers to informed consent.

Any health care provider can determine whether a patient has decision-making capacity by asking some simple questions that check for understanding and appreciation of circumstances, as well as rational decision making (22). To assess understanding, one can ask, What do you understand to be your current situation? What are your treatment options? What will happen when you take this treatment? To assess appreciation, one can ask, What makes you not want this treatment? (for patients who are refusing), Why do you want it? (for patients who have consented), What other choices do you have? Finally, to assess rationality, one can ask, Why have you made this decision? How did you arrive at your choice? What questions do you have? What are you worried about?

If patients' answers to capacity-assessment questions indicate that they may not understand and appreciate their circumstances, or that they are not making rational decisions, then the health care provider's ethical obligation is to delay therapy until the supervising or treating physician can be notified and a surrogate decision maker can be identified. When patients have no identifiable surrogate decision maker, an ethics consultant should be called or a hospital attorney can advise accordingly about state laws (i.e., family hierarchy laws) and institutional practice agreements.

\section{Capacity Versus Competency}

It is critical to understand the difference between capacity and competency. Decision-making capacity refers to an adequate degree of capacity for medical decisions and is task-specific. Capacity can change over short periods of time; for example, when thyroid cancer patients are prepped for a radioactive iodine scan or therapy by being made severely hypothyroid, they may not have the capacity to consent at that time but would have capacity once they are euthyroid (23). Thus, decision-making capacity refers to an ability to make a medical decision at a particular point in time. Competency, however, refers to a property or characteristic a person possesses that is of a more permanent nature. For example, mentally disabled patients, children or adolescents under 18 (unless they are an emancipated minor), or patients with advanced dementia are not competent, and that condition is going to persist over long periods of time $(21,24,25)$.

\section{Voluntariness}

Autonomy-based decisions are freely made: patients are asserting agency and independence and are authentically representing their values, plans, and preferences. Autonomous decisions also reflect deliberation (rationality) and demonstrate moral reflection.

Is the patient being allowed to make a health care choice free of any undue influences? To answer that question, one needs to take into consideration internal factors such as pain and discomfort, as well as external factors such as manipulation, which involves "the deliberate distortion or omission of information" in an attempt to induce patients to accept the therapy (19). For example, the Internet is filled with misinformation about nuclear medicine procedures that can interfere with informed consent (26).

For patients who refuse procedures, the supervising physician should be called to reassess the patient for the procedure, or an ethics consultant could be called if the supervising physician is unavailable and it is unclear what to do. Procedures should be delayed when patients are refusing.

\section{Surrogate Decision Making}

To protect autonomy, persons who cannot make decisions for themselves require a surrogate to make a substitute decision according to the patient's preferences, if known, or in the patient's best interests if preferences are not known. If patient preferences are known but the surrogate decision maker is making a decision that is contrary to the patient's expressed wishes, the surrogate is not fulfilling the role appropriately. In these cases, a different surrogate may be necessary. Unless patients directly name a surrogate decision maker or appoint someone to have medical power of attorney, state family hierarchy laws may appoint family members as surrogate decision makers. This situation can be problematic if family members are estranged or dysfunctional. Patients with no family members or potential surrogates may require state guardianship; in many states and institutions, the treating physician can make a substitute judgment in the patient's best interests.

In the case of children, although parents and guardians have decision-making authority, pediatric assent should be obtained from older children and adolescents $(27,28)$. Historically, the concept of pediatric assent began to attract serious analysis and scholarship around the mid-1990s. A consensus statement on this issue by the American Pediatric Association's Committee on Bioethics was published in Pediatrics in 1995 (29). This document clarifies that children and adolescents should be included in all decisions unless there is a good reason to exclude them; refusals should be taken seriously and honored for all procedures that have no direct benefit or that are elective and can be delayed; health care providers should empower children in decision making to the extent of the child's capacity; and in the case of an adolescent, the capacity to make a decision is usually high. Ultimately, the American Pediatric Associa- 
tion recognizes that "informed consent" as a concept in adult care needs to be replaced with the dual concept of parental permission and pediatric assent.

\section{CONCLUSION}

Informed consent as an ethical and legal concept is not a signature on a consent form (1) but an involved process that includes considerable discussion with patients so they can make an informed decision. Barriers to informed consent include wide gaps in knowledge, literacy, and numeracy (particularly when explaining the nature of radioactive isotopes). Language barriers; mental health issues such as addiction, anxiety, and depression; and religious belief systems can all affect how patients filter complex information.

When nuclear medicine technologists are faced with obtaining informed consent, they must first decide if they are qualified to properly obtain such consent from a patient, as they may not have the fund of knowledge necessary to explain why various procedures are being ordered and what the goals of care are. If informed consent is necessary and the nuclear medicine health care provider cannot properly obtain that consent, the procedure should be delayed until the treating physician has been located to obtain proper consent.

\section{ACKNOWLEDGMENTS}

I thank Elpida S. Crawford, CNM, clinical associate professor and NMT program director at the University at Buffalo, for guidance on all content that outlines which procedures require informed consent in the nuclear setting.

\section{REFERENCES}

1. Jones JW, McCullough LB, Richman BW. Informed consent: it's not just signing a form. Thorac Surg Clin. 2005;15:451-460.

2. Hopper KD, TenHave TR, Hartzel J. Informed consent forms for clinical and research imaging procedures: how much do patients understand? AJR. 1995;164: 493-496.

3. Nuckols TK, Bhattacharya J, Wolman DM, Ulmer C, Escarce J. Cost Implications of reduced work hours and workloads for resident physicians. $N$ Engl J Med. 2009;360:2202-2215.
4. Canterbury v Spence, 464 F2d 772 (DC Cir 1972).

5. Cobbs v Grant, 8 Cal 3d 229, 502 P2d 1, 104 Cal Rptr 505 (Cal 1972).

6. Wilkinson $v$ Vesey, 110 RI 606, 624 (1972).

7. The Nuremberg Code. Office of Human Subjects Research Web site. Available at: http://ohsr.od.nih.gov/guidelines/nuremberg.html. Accessed January 6, 2011

8. Faden RR, Lederer SE, Moreno JD. US medical researchers, the Nuremberg Doctors Trial, and the Nuremberg Code: a review of the findings of the Advisory Committee on Human Radiation Experiments. JAMA. 1996;276:1667-1671.

9. Human radiation experiments associated with the U.S. Department of Energy and its predecessors. Office of Health, Safety and Security Web site. Available at: http://www.hss.energy.gov/HealthSafety/ohre/roadmap/experiments/index.html. Accessed January 11, 2011.

10. McNeil DG. U.S. apologizes for syphilis tests in Guatemala. New York Times. October 2, 2010:A1

11. Beecher HK. Ethics and clinical research. N Engl J Med. 1966;274:1354-1360.

12. The Belmont Report: ethical principles and guidelines for the protection of human subjects of research. Office of Human Subjects Research Web site. Available at: http://ohsr.od.nih.gov/guidelines/belmont.html. Accessed January 6, 2011.

13. Milgram S. Obedience to Authority. New York, NY: Harper; 1974.

14. Haney C, Banks WC, Zimbardo P. Interpersonal dynamics in a simulated prison. Int J Criminology Penology. 1973;1:69-97.

15. Etchells E, Sharpe G, Walsh P, Williams JR, Singer PA. Bioethics for clinicians: 1. consent. CMAJ. 1996;155:177-180.

16. Etchells E, Sharpe G, Burgess MM, Singer PA. Bioethics for clinicians: 2. disclosure. CMAJ. 1996;155:387-391.

17. Dickens BM, Cook RJ. Dimensions of informed consent to treatment. Int $J$ Gynaecol Obstet. 2004;85:309-314.

18. Etchells E, Sharpe G, Elliott C, Singer PA. Bioethics for clinicians: 3. capacity. CMAJ. 1996;155:657-661.

19. Etchells E, Sharpe G, Dykeman MJ, Meslin EM, Singer PA. Bioethics for clinicians: 4. voluntariness. CMAJ. 1996;155:1083-1086.

20. Veatch RM. Abandoning informed consent. Hastings Cent Rep. 1995;25:5-12.

21. Buchanan A, Brock D. Deciding for Others: The Ethics of Surrogate DecisionMaking. New York, NY: Cambridge University Press; 1989.

22. Wenger N. Improving end of life decisions and pain management. Lecture presented at: University of Kentucky Program for Bioethics; April 12, 2005; Lexington, Kentucky.

23. Rosenthal MS. The impaired hypothyroid patient: ethical considerations and obligations. Thyroid. 2007;17:1261-1267.

24. Culver CM, Gert B. Competence. In: Radden J, ed. The Philosophy of Psychiatry: A Companion. Oxford, U.K.: Oxford University Press; 2004:258-270.

25. Roth LH, Meisel A, Lidz CW. Tests of competency to consent to treatment. Am J Psychiatry. 1977;134:279-284.

26. Rosenthal MS. Ethical problems with patient misconceptions in RAI scans and therapy. J Nucl Med Technol. 2006;34:143-150.

27. Emanuel EJ, Emanuel LL. Proxy decision-making for incompetent patients: an ethical and empirical analysis. JAMA. 1992;267:2067-2071.

28. Bartholome WG. A new understanding of consent in pediatric practice: consent, parental permission and child assent. Pediatr Ann. 1989;18:262-265.

29. Informed consent, parental permission, and assent in pediatric practice. American Pediatric Association Committee on Bioethics. Pediatrics. 1995;95: 314-317. 